Entorno Geográfico | № 22 | julio-diciembre 2021 | pp. 56-78 | ISSN (en línea): 2382-3518 / ISSN impreso: 1692-0074 | Universidad del Valle

DOI: 10.25100/eg.v0i22.11346

Espacios y Territorios

\title{
Zonificación urbana y el género como una de las variables en su conformación. División funcional en la zona metropolitana de Monterrey (ZMM), Nuevo León, México
}

\section{Urban zoning and gender as one of the variables in its conformation. Functional division in the Monterrey metropolitan zone (MMZ), Nuevo León, Mexico}

\author{
Malinalli Hernández-Reyes \\ Instituto Tecnológico y de Estudios Superiores de Monterrey (ITESM), Monterrey, México. \\ malinallih@yahoo.com | 0000-0003-4140-9673
}

\begin{abstract}
Para citar este artículo: Hernández-Reyes, M. (2021). Zonificación urbana y el género como una de las variables en su conformación. División funcional en la zona metropolitana de Monterrey (ZMM), Nuevo León, México.

Entorno Geográfico, (22), 56-78. https://doi.org/ 10.25100/eg.v0i22.11346
\end{abstract}

\section{Resumen}

El estudio aquí expuesto forma parte de una investigación de mayor alcance cuyo contexto corresponde a la zona metropolitana de Monterrey (ZMM), México. Tiene la finalidad de dar a conocer la metodología utilizada para determinar si el territorio de la ZMM corresponde al de un espacio zonificado o dividido en funciones. Asimismo, este trabajo aspira a estimular la reflexión en torno a posibles conexiones entre la zonificación urbana y las asunciones y modelos sociales relacionados con la asignación de espacios, físicos y sociales, a razón del género. La aproximación metodológica aquí brindada se vale de la actividad económica-representada específicamente por las unidades económicas (UE) existentes en la ZMM en 2010 y el sector al que pertenecen-como único indicador para la diferenciación de las funciones urbanas de la metrópoli. Los resultados se presentan en mapas temáticos que hablan del nivel de concentración de UE por municipio; estos ratifican la condición zonificada de la ZMM y evidencian la concentración geográfica de su economía.

Palabras clave: zona metropolitana de Monterrey, zonificación urbana, género.

\begin{abstract}
The study presented here is part of a larger research project whose context corresponds to the Monterrey metropolitan zone (MMZ), Mexico. Its purpose is to present the methodology used to determine whether the territory of the MMZ corresponds to that of a zoned space or a space divided into functions. Likewise, this work aims to stimulate reflection on possible connections between urban zoning and social assumptions related to the allocation of physical and social spaces based on gender. The methodological approach provided here makes use of the economic activity specifically represented by 2010 MMZ's economic units (UE) and the sector to which they belongas the unique differentiation factor of the metropolis urban functions. The results are presented in
\end{abstract}


thematic maps that speak of the UE concentration by municipality which ratifies the zoned condition of the MMZ and highlight the geographic concentration of its economy.

Key words: Monterrey metropolitan zone, zoning, gender.

Recibido: 19 de febrero de 2021

Aceptado: 05 de abril de 2021

\section{Introducción}

El estudio expuesto en este documento forma parte de los argumentos utilizados en la discusión y las conclusiones del trabajo doctoral de la autora, cuyo alcance es mayor. Los objetivos perseguidos en la realización de dicho estudio son dos: 1) enmarcar o situar la actividad remunerada de las mujeres de la zona metropolitana de Monterrey (ZMM), México, uno de los principales tópicos del trabajo doctoral mencionado; 2) determinar si el contexto territorial de estudio, la ZMM, corresponde al de un espacio dividido en funciones mediante el examen de su actividad económica. De confirmarse, la zonificación de la ZMM estaría afectando los desplazamientos urbanos de su población, en particular, los desplazamientos laborales de las mujeres que desempeñan un doble rol al interior de sus hogares, el productivo y el reproductivo, tema central de la referida investigación doctoral.

A partir de lo anterior, la finalidad del presente documento es dar a conocer la metodología y los resultados del estudio aludido, que en sí mismo constituye una investigación completa basada en un análisis de datos serios y rigurosos. El interés se centra en el segundo de los objetivos planteados y se formula la pregunta: ¿cómo es la configuración espacial de la ZMM; se trata de un territorio dividido a nivel funcional? Ante ella se propone la hipótesis de que la ZMM es un 'todo urbano' compuesto por partes especializadas en tareas concretas representadas por cada una de las demarcaciones municipales que lo integran, es decir, un espacio zonificado o fragmentado en sus funciones urbanas. Por otra parte, y en línea con la disertación en la que se encuadra, este texto busca exponer, desde la geografía de género y a nivel teórico, que el género es un factor más en la construcción social de la ciudad que se refleja en la segregación o fragmentación del espacio construido, lo que refuerza la separación de las esferas pública y privada. Ello justificaría el interés por evidenciar la zonificación urbana de la ZMM.

En orden de alcanzar los propósitos señalados, a esta introducción le sigue la base teórica que aborda la fragmentación de la ciudad desde la variable del género, en una segunda sección; la tercer sección describe la metodología utilizada en el análisis de los datos de la ZMM, territorio elegido como contexto de estudio; un cuarto apartado se dedica a la descripción de esa demarcación metropolitana; los resultados del estudio y su discusión se detallan en el quinto apartado, en el cual se examina información de índole económica que ayuda a perfilar, en un nivel funcional, a cada uno de los municipios que integran la ZMM. Una sexta sección está destinada a la exposición de las conclusiones y de algunas reflexiones finales.

\section{El factor del género en la conformación del espacio urbano zonificado}

Existen dos aspectos en la conformación de la ciudad, a saber, el físico y el social, ubicados siempre en un lugar y en un momento específicos. El primero se relaciona con la organización y disposición en el espacio tanto de individuos como de edificios; el segundo es el que se construye desde la 
estructura social impulsada por variables como la economía, la político-institucional, la tecnología, la cultura y la ideología (Borja \& Muxí, 2003; Castells, 1978; Harvey, 2013; Hillier \& Hanson, 1984; Inam, 2013; Lefebvre, 1978; Lezama, 2014; Massey, 1994; Sassen, 2014; Soja, 1996; Wilson, 1992).

Massey (1994) argumenta que los espacios y los lugares hegemónicos no son influenciados únicamente por cuestiones económicas, sino que en su modelado también intervienen relaciones sociales e ideológicas como las dadas por el género, por lo que se le ha de considerar a éste como una variable más con implicaciones tangibles en la conformación del espacio urbano.

Para comprender lo anterior, es necesario señalar que el género es un constructo conceptual o categoría de estudio aportada por la teoría feminista y ubicada dentro de un sistema social hegemónico de dominio masculino, el denominado patriarcado. El sistema patriarcal ha establecido un espacio público-político "diseñado por los varones y para los varones, mientras que el espacio privado-doméstico ha sido creado por los varones para las mujeres” (Cobo, 2014, p.10). Está conformado por normas sociales en las que precisamente el género actúa como "principio de jerarquización que asigna espacios y distribuye recursos a varones y mujeres" (Cobo, 2014, p.9).

La categoría de género es producto del hallazgo de la incidencia sociocultural en la construcción, dicotómica y polarizada, de la feminidad y la masculinidad, ambas supuestamente vinculadas a la naturaleza biológica de los individuos (Castro, 2009; Cobo, 2014).

De acuerdo con Castro (2009, p.112), “[a] través de dicha categoría fue posible reflexionar sobre cómo se había normalizado, a lo largo de la historia, la desigualdad entre hombres y mujeres, y de qué forma la adscripción a un sexo o a otro determinaba los papeles que el sujeto debía desempeñar". La autora reconoce la capacidad explicativa y transformadora de esta categoría de análisis, ya que por medio de ella es posible evidenciar de qué manera lo simbólico se proyecta en la realidad social, traducido en los "espacios de subordinación, discriminación y opresión de las mujeres en cada sociedad” (Cobo, 2014, p.9).

Según la teoría feminista, la relación entre las categorías sociales de hombre y mujer se inscribe dentro del ámbito del poder en donde el hombre es quien domina y la mujer es quien se subordina (Beauvoir, 2005; Cobo, 2014; Mcdowell, 2000; Valcárcel, 2009). Estas categorías representan y/o son resultado de binomios o dicotomías como masculino/femenino, dominación/subordinación, fuerza/debilidad, producción/consumo, producción/reproducción, entre otras (Mcdowell, 2000; Saborido, 1999).

Es probable que el último binomio mencionado, el de producción/reproducción, derive de la concepción tradicional de que los 'atributos naturales' del hombre son brindar protección y ser la fuente del ingreso económico familiar, mientras que los de la mujer son ser madre, cuidadora y esposa (Beauvoir, 2005; Mcdowell, 2000; Moser, 1989; Valcárcel, 2009).

Tal modelo, históricamente instaurado e identificado por los estudios feministas como el principio organizador de la sociedad (Massey, 1994; Mcdowell, 2000), ha sido fundamental a la hora de ubicar a la mujer principalmente en el ámbito doméstico y restringir su presencia en la esfera pública; de ahí las dicotomías relacionadas al espacio urbano como fuera/dentro, público/privado, urbano/doméstico, trabajo/casa, por mencionar algunas.

De acuerdo con Massey (1994) y Mcdowell (2000), son esas divisiones binarias, en términos generales, las que influyen en la construcción social del espacio del mismo modo que el resto de 
las variables enunciadas al comienzo de este apartado, y están siendo reproducidas principalmente en su partición y subsecuente asignación a cada categoría de género, hecho que se ve reforzado con el proceso de industrialización (Col·lectiu Punt 6, 2019).

Fue principalmente en el siglo XIX y en el contexto europeo que, a raíz de la revolución industrial y del consecuente crecimiento acelerado de la ciudad, la división del trabajo se acentuó al tiempo que se consolidó la escisión - social y espacial- entre lo público y lo privado (Darke, 1998). Mientras antaño las actividades productivas se realizaban en el mismo espacio en el que se habitaba, ahora estas labores son llevadas a cabo lejos de él, por lo que la mujer se ve separada del trabajo productivo y se limita al desempeño del trabajo reproductivo y de cuidado, ligado fuertemente al espacio doméstico (Arredondo, Maldonado, \& Velázquez, 2013; Karsten \& Meertens, 1992; Massey, 1994; Mcdowell, 2000). Por su parte, al hombre se le atribuyó el papel de proveedor y se le ligó al espacio público, es decir, el ámbito laboral y de la actividad productiva (Cuvardic, 2011; Sewell, 2011).

El crecimiento de la actividad manufacturera trajo consigo la emergencia de una serie de actividades que modelaron el entorno construido de la esfera pública: se erigieron "fábricas, oficinas, estaciones de ferrocarril, clubes, entidades profesionales, universidades, bolsas, salas de conciertos, ayuntamientos, campos de deportes, bibliotecas, tiendas y grandes almacenes" (Darke, 1998, p.124), espacios en donde dominaba la presencia masculina. A la par, "[1]a suburbanización era la expresión física de lo que se percibía como el papel principal de las mujeres: esposa y madre, administradora de un hogar que sirviera de refugio para reposar y huir del ajetreo de la vida pública" (ibidem), papel que ni la clase trabajadora ni la clase media podían eludir.

La división espacial y conceptual entre casa y trabajo es, pues, un evento relativamente reciente. A principios del siglo XX fue incentivada por el urbanismo iluminista, ordenador y racional, ya que su intervención diferenció los usos del suelo en comercial, industrial y residencial a través de la zonificación funcional de la ciudad (García, 2016). Esta circunstancia consintió a intereses primordialmente mercantiles (García, 2016; Lezama, 2014; Mumford, 1961); sin embargo, también favoreció al establecimiento de la agenda moral "que creó la domesticidad como un ideal de vida" (Connell, 2005, p.370), apoyada en el modelo organizador de la sociedad basado en la diferenciación sexual.

Esa organización espacial de la ciudad prevalece hasta nuestros días, y es posible reconocer en ella la "proyección de la propia división sexual del trabajo" (Col·lectiu Punt 6, 2019), materializada en la zonificación urbana, esto es, la separación o segregación física de zonas residenciales y centros de trabajo, principalmente (Darke, 1998).

Es importante, por tanto, "investigar y sacar a la luz la relación que hay entre las divisiones de género y las divisiones espaciales, para descubrir cómo se constituyen mutuamente, y mostrar los problemas ocultos tras su aparente naturalidad" (Mcdowell, 2000, p.27). Y si bien es verdad que este esfuerzo de investigación no tiene el fin de develar la influencia recíproca señalada, también es cierto que una de las fases preliminares para dicho cometido sería la de establecer que el espacio urbano cuestionado está efectivamente dividido o zonificado, objetivo que sí se ha propuesto. 


\section{Materiales y método}

De acuerdo con Garza (2004), la expansión demográfica y urbana de las ciudades está altamente determinada por su dinámica económica, y esta, a su vez, define en gran medida la especialización del territorio, es decir, su perfil o carácter funcional.

A raíz de ello se decide analizar las unidades económicas ${ }^{1}$ (UE) -establecimientos manufactureros, comerciales y de servicios de toda clase- existentes en cada municipio integrante de la ZMM, con particular atención en el sector económico al que pertenecen, con el fin de esbozar su vocación económica y con ello, estimar su función dentro del todo metropolitano.

Se reitera que el presente trabajo es parte de una disertación más extensa para cuya ejecución se recurrió a la información poblacional brindada por la Muestra censal del Censo de Población y Vivienda 2010 (INEGI, 2010b), debido a la conveniencia de sus datos y por ser la fuente más reciente y fidedigna al momento del desarrollo de la investigación.

De modo que la temporalidad de los datos sea la misma, la información económica consultada para el análisis que aquí nos ocupa es la generada por el Sistema Nacional de Información Estadística y Geográfica (SNIEG), coordinado por el Instituto Nacional de Estadística y Geografía (INEGI), disponible a través del Directorio Estadístico Nacional de Unidades Económicas 2010 (DENUE) (INEGI, 2010a).

El examen de la información referida persigue establecer la concentración de UE por sector de actividad y por municipio de dos formas: 1) en números absolutos a partir de la distribución de UE de cada sector económico a nivel municipal sobre el total metropolitano; y 2) en números relativos a partir de la tasa de UE por sector económico de cada municipio sobre el total municipal. Ambos aspectos se presentan en sendos conjuntos de mapas temáticos.

Con objeto de alcanzar resultados y conclusiones más precisas en torno a la zonificación metropolitana, se consideran las tasas de crecimiento poblacional del período 2000-2010, a fin de establecer cuáles son las demarcaciones en las que la población tendió más fuertemente a residir, así como los porcentajes de población cuya actividad económica se localiza en un municipio distinto al de su residencia para 2010 SEDESOL et. al (2012).

\section{La zona metropolitana de Monterrey (ZMM)}

Localizada en la entidad federativa de Nuevo León, en el noreste de la República Mexicana (Figura 1), la ZMM ha tenido un gran desempeño comercial e industrial impulsado por su condición fronteriza con los Estados Unidos de Norteamérica. Tanto el sur de Texas como los Estados mexicanos de Coahuila y Tamaulipas han ocupado un papel protagónico en su desarrollo económico (Cavazos, 1995).

La metropolización ${ }^{2}$ de la ZMM es originada por la industrialización de su economía, y afianzada más tarde por la terciarización ${ }^{3}$. La expansión territorial acelerada del municipio central de

${ }^{1}$ Unidad económica es la "unidad de observación sobre la cual se solicita y se publica información de carácter económico; ésta puede ser establecimiento único, matriz o sucursal, y fijo o semifijo" (INEGI, 2010c).

${ }^{2}$ Las etapas de metropolitanismo se caracterizan por el desplazamiento territorial centro-periferia de población y de actividad económica (Sobrino, 2003).

${ }^{3}$ La Revolución Terciaria (terciarización, servicialización) es la importancia que ha ganado el sector económico terciario frente al secundario, el que ha visto disminuidos sus niveles de empleabilidad y de producción (Contreras, 2007; Vásquez, 2009). 
Monterrey (R. García \& Garza, 1995) y la consecuente conurbación con sus municipios lindantes, es característica de los mencionados procesos.

Fuente: Elaboración propia del territorio mexicano con datos del INEGI (2010e).

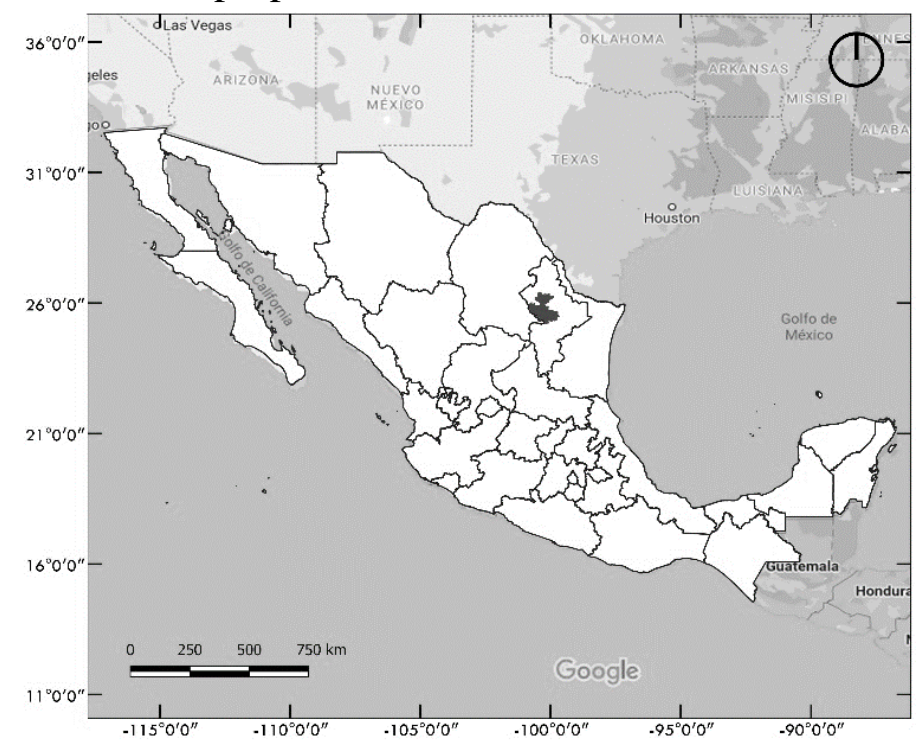

Figura 1. Localización geográfica de la ZMM al interior del territorio mexicano.

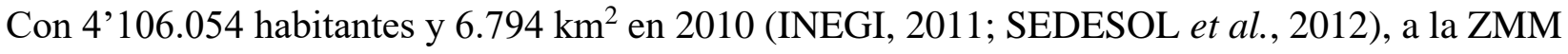
la constituían entonces trece municipios: Apodaca, Cadereyta Jiménez, Carmen, García, San Pedro Garza García, General Escobedo, Guadalupe, Juárez, Monterrey, Salinas Victoria, San Nicolás de los Garza, Santa Catarina y Santiago (Figura 2).

Fuente: Elaboración propia con datos del INEGI (2010e).

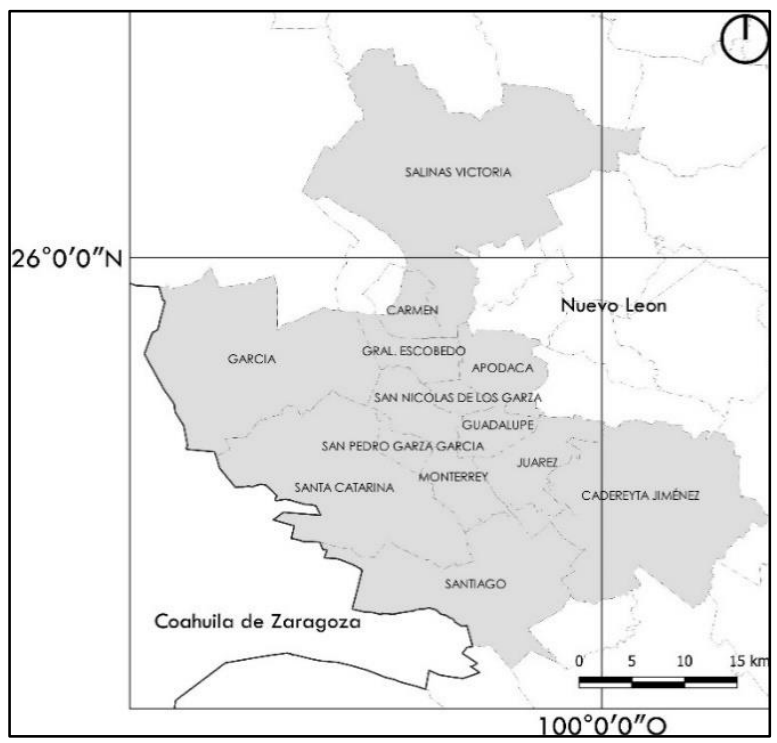

Figura 2. Municipios de la ZMM en 2010. 


\section{Resultados y discusión. Configuración funcional de la ZMM 2010}

Si bien autores como Garza (1995a) o Sousa (2010) han llevado a cabo ejercicios dedicados a exponer la organización espacial de la ZMM mediante la identificación y descripción de las zonas que la conforman, la información por ellos empleada es anterior a la requerida en este trabajo. El primero recaba datos de la década de 1990; el segundo, del lapso de 2000-2005. Por ese motivo se realiza una revisión propia de la metrópoli en su nivel funcional, en el contexto de la disertación ya comentada, revisión que a continuación se detalla.

La Figura 3 presenta la distribución municipal de las UE que en julio de 2010 existían en toda la ZMM. Con una tasa del $42.61 \%$ de un total de 135548 UE, no es ninguna sorpresa que el municipio de Monterrey concentre a la gran mayoría de éstas, lo que confirma la prevalencia en el tiempo de su dominio metropolitano como centralidad urbana. Muy por detrás lo siguen Guadalupe y San Nicolás con el $15.29 \%$ y el $11.09 \%$, respectivamente.

Fuente: Elaboración propia a partir de los datos del DENUE (INEGI, 2010a).

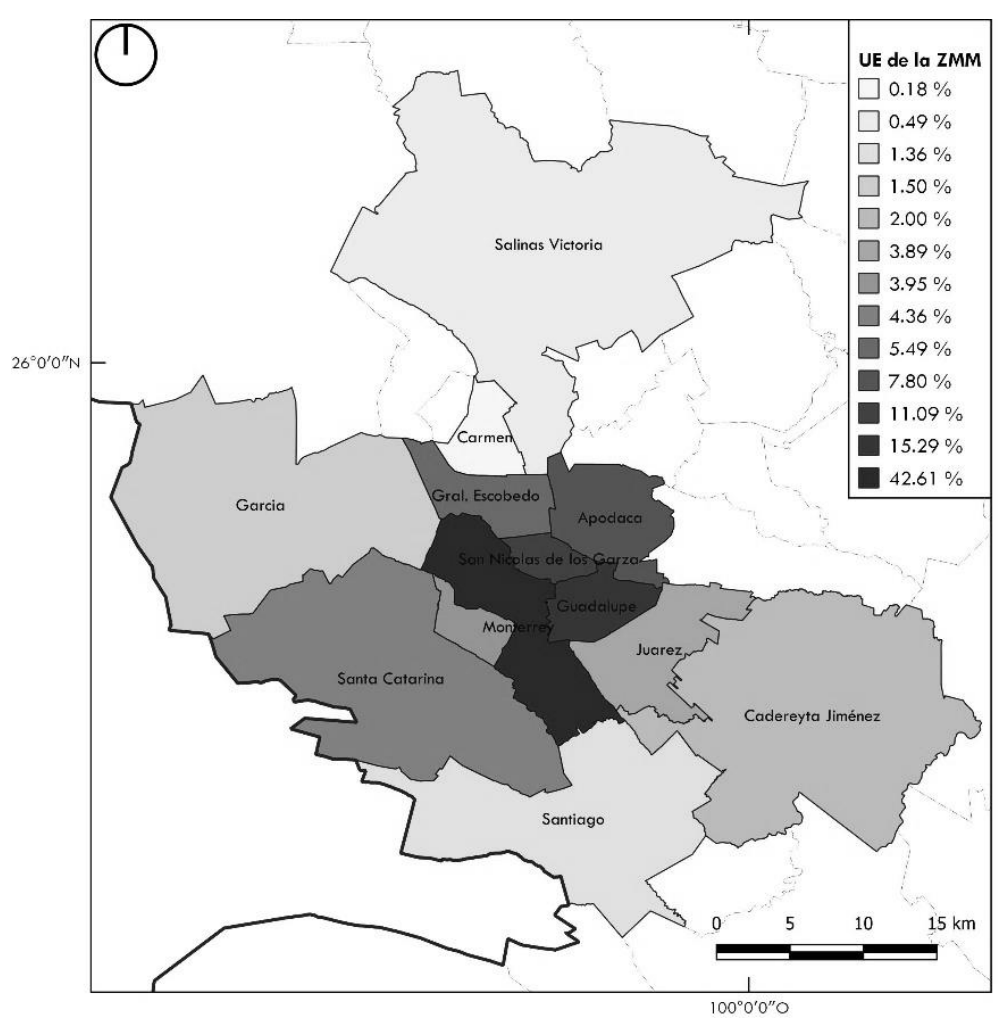

Figura 3. Distribución geográfica del total de unidades económicas de la zona metropolitana de Monterrey (ZMM).

Cada uno de los diez municipios restantes no alcanzan a concentrar ni el 10\% de las UE; juntos, suman apenas el 31.02\% del total de la ZMM. Desagregar los datos de las UE por actividad económica no genera ningún cambio, de acuerdo a las Figuras 4 y 5. Monterrey mantiene la centralidad en los tres tipos de actividad (aunque la primaria se desestima en esta investigación debido a su inminente desaparición de la ZMM), y es seguido por los mismos cinco municipios: Guadalupe, San Nicolás, Apodaca, Escobedo y Santa Catarina, en ese orden. El municipio con los 
porcentajes más bajos de UE es, en cualquiera de los casos, Carmen, localizado en la parte norte de la ZMM, lo que evidencia su reciente adhesión a la metrópoli ${ }^{4}$. Ello denota el esperado desequilibrio económico entre el centro y la periferia metropolitanos.

La ZMM observa una cantidad de UE vinculadas a la actividad secundaria mucho menor en comparación al número de UE terciarias. Las primeras hacen un total de 13.083 (Figura 4), es decir, el $9.65 \%$ del total de UE de la ZMM, mientras que las segundas ascienden a 122.452 (Figura 5), lo que representa el $90.34 \%$ sobre el mismo total.

Es importante señalar que la actividad terciaria comprende 15 sectores distintos de actividad, los cuales se agrupan de acuerdo a sus principales características. La Tabla 1 relaciona a todos ellos. Hay que aclarar que las actividades $G$ no son consideradas aquí pues, más que ser del tipo económico per se, son normativas o reguladoras del resto de las actividades (INEGI, 2010d). El resto de las omisiones (OI y OA), se realizaron por su baja presencia en la ZMM.

Fuente: Elaboración propia a partir de los datos del DENUE (INEGI, 2010a).

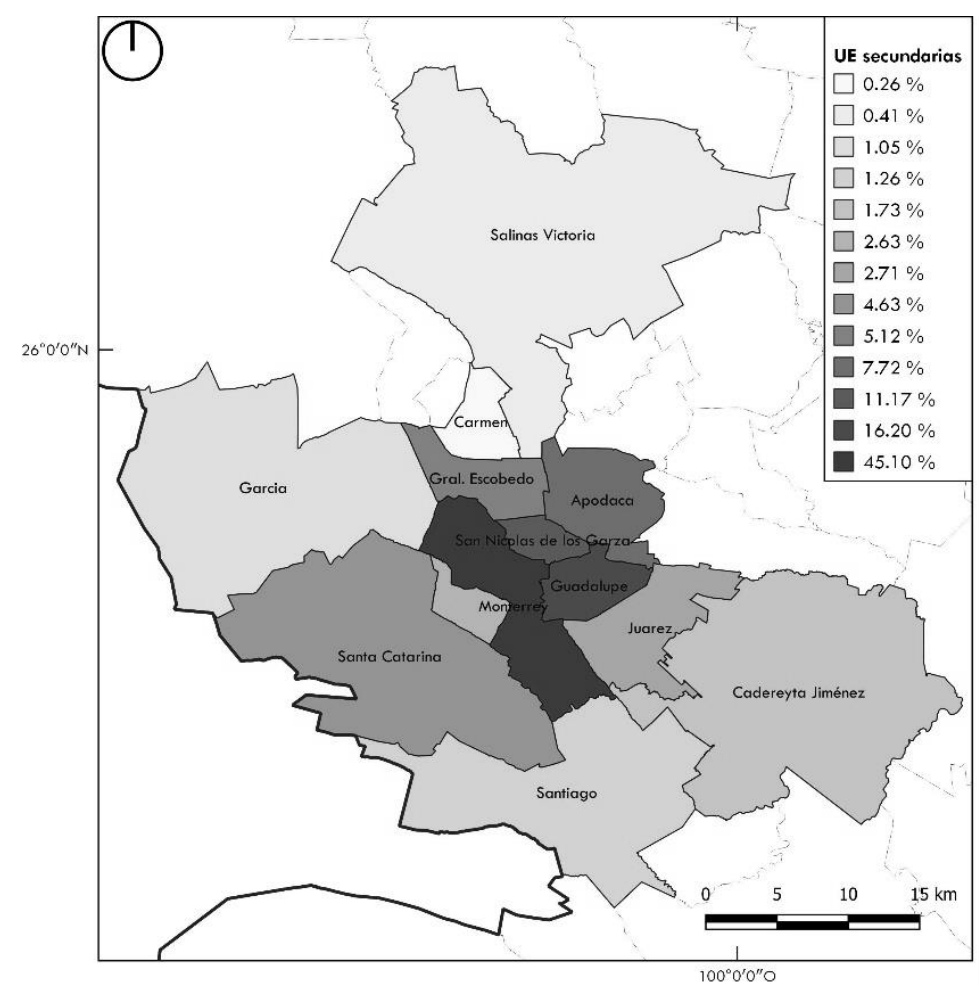

Figura 4. Distribución geográfica de unidades económicas dedicadas a la actividad secundaria en la zona metropolitana de Monterrey (ZMM).

${ }^{4}$ La SEDESOL et al. lo contemplan dentro de la ZMM hasta después del Censo de población y vivienda 2010 (SEDESOL et al., 2004, 2012). 
Fuente: Elaboración propia a partir de los datos del DENUE (INEGI, 2010a).

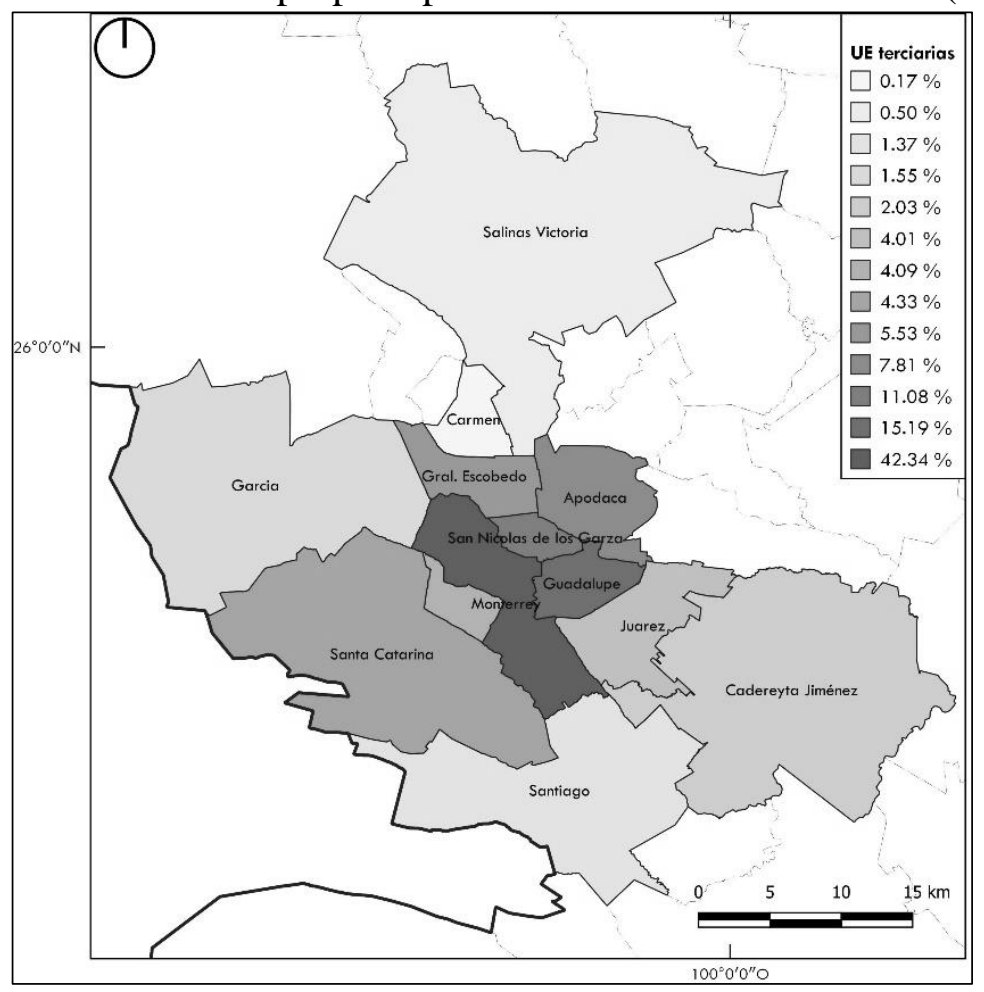

Figura 5. Distribución geográfica de unidades económicas dedicadas a la actividad terciaria en la zona metropolitana de Monterrey (ZMM).

Tabla 1. Actividad económica terciaria desagregada por sector

\begin{tabular}{|c|c|c|c|}
\hline $\mathrm{N}^{\circ}$ & Sector & Sector general & Abreviación \\
\hline 1 & Comercio al por mayor & \multirow{3}{*}{$\begin{array}{l}\text { Distribución de } \\
\text { bienes }\end{array}$} & \multirow{3}{*}{ DB } \\
\hline 2 & Comercio al por menor & & \\
\hline 3 & Transportes, correos y almacenamiento & & \\
\hline 4 & Información de medios masivos & $\begin{array}{l}\text { Operaciones con } \\
\text { información }\end{array}$ & OI \\
\hline 5 & Servicios financieros y de seguros & \multirow[b]{2}{*}{$\begin{array}{l}\text { Operaciones con } \\
\text { activos }\end{array}$} & \multirow[b]{2}{*}{ OA } \\
\hline 6 & $\begin{array}{l}\text { Servicios inmobiliarios y de alquiler de bienes } \\
\text { muebles e intangibles }\end{array}$ & & \\
\hline 7 & Servicios profesionales, científicos y técnicos & \multirow{3}{*}{$\begin{array}{c}\text { Servicios } \\
\text { profesionales } \\
\text { especializados }\end{array}$} & \multirow{3}{*}{ SPE } \\
\hline 8 & Corporativos & & \\
\hline 9 & $\begin{array}{l}\text { Servicios de apoyo a los negocios y manejo de } \\
\text { desechos y servicios de remediación }\end{array}$ & & \\
\hline 10 & Servicios educativos & \multirow{2}{*}{$\begin{array}{c}\text { Servicios } \\
\text { educativos y de } \\
\text { salud }\end{array}$} & \multirow[b]{2}{*}{ SES } \\
\hline 11 & Servicios de salud y de asistencia social & & \\
\hline 12 & $\begin{array}{l}\text { Servicios de esparcimiento culturales } \\
\text { deportivos, y otros servicios recreativos }\end{array}$ & $\begin{array}{l}\text { Servicios } \\
\text { recreativos }\end{array}$ & SR \\
\hline
\end{tabular}




\begin{tabular}{|c|c|c|c|}
\hline $\mathrm{N}^{\circ}$ & Sector & Sector general & Abreviación \\
\hline 13 & $\begin{array}{l}\text { Servicios de alojamiento temporal y de } \\
\text { preparación de alimentos y bebidas }\end{array}$ & & \\
\hline 14 & $\begin{array}{l}\text { Otros servicios excepto actividades } \\
\text { gubernamentales }\end{array}$ & $\begin{array}{l}\text { Servicios } \\
\text { residuales }\end{array}$ & OS \\
\hline 15 & $\begin{array}{l}\text { Actividades legislativas, gubernamentales, de } \\
\text { impartición de justicia y de organismos } \\
\text { internacionales y extraterritoriales }\end{array}$ & $\begin{array}{c}\text { Actividades } \\
\text { gubernamentales }\end{array}$ & G \\
\hline
\end{tabular}

Fuente: Elaboración propia a partir del SCIAN 2007 (INEGI, 2010d).

Ahora bien, si se considera a la actividad terciaria desagregada por sectores de actividad, la situación no es muy distinta a lo que los tres mapas precedentes han dejado notar. La Figura 6 indica que el municipio de Monterrey es el indiscutible polo económico de la ZMM, pues en todos los sectores terciarios analizados concentra arriba del 40\% del total de las UE; le siguen Guadalupe y San Nicolás, en casi la totalidad de los sectores, con porcentajes que no alcanzan a promediar el $13 \%$. Por su parte, Carmen aparece nuevamente en el último puesto de todas las listas, con valores que no llegan al $1 \%$.

Como en las figuras anteriores, a partir del cuarto puesto y hacia el final de la lista se observan cifras menores al $10 \%$.

Hay un caso que es necesario comentar por su importancia financiera y de negocios dentro de la ZMM: el municipio de San Pedro Garza García. Este se coloca en el tercer puesto, después de Monterrey y Guadalupe, de la lista de los SPE, protagonistas de la actividad terciaria de ese municipio, pues ostenta el $10.17 \%$ del total de las UE dedicadas a la oferta de los llamados servicios al productor en toda la ZMM.

Aunque lo que más llama la atención es el caso del municipio de Guadalupe, que pasó de área dormitorio en la década de los años noventa (Pozas, 1995), a ocupar el segundo puesto en la lista de concentración de UE de cualquier giro. Si bien es cierto que se ubica muy por detrás de las tasas del municipio de Monterrey, es de admirar que aparezca delante de San Nicolás, territorio que se había distinguido por su perfil industrial y, en años más recientes, comercial (Rivera, 1995b; Vásquez, 2009).

Dado que los mapas de la Figura 6 se elaboran sobre el total de las UE de toda la ZMM (números absolutos), es interesante efectuar el mismo ejercicio a partir de los totales municipales (números relativos) de UE dedicadas a cada sector de actividad económica para así desvelar la verdadera vocación municipal. La Tabla 2 es de utilidad para la revisión de los mapas generados bajo este nuevo criterio, ya que ofrece tanto los totales de UE existentes como las específicamente dedicadas a la actividad terciaria. 
Fuente: Elaboración propia a partir de los datos del DENUE (INEGI, 2010a).
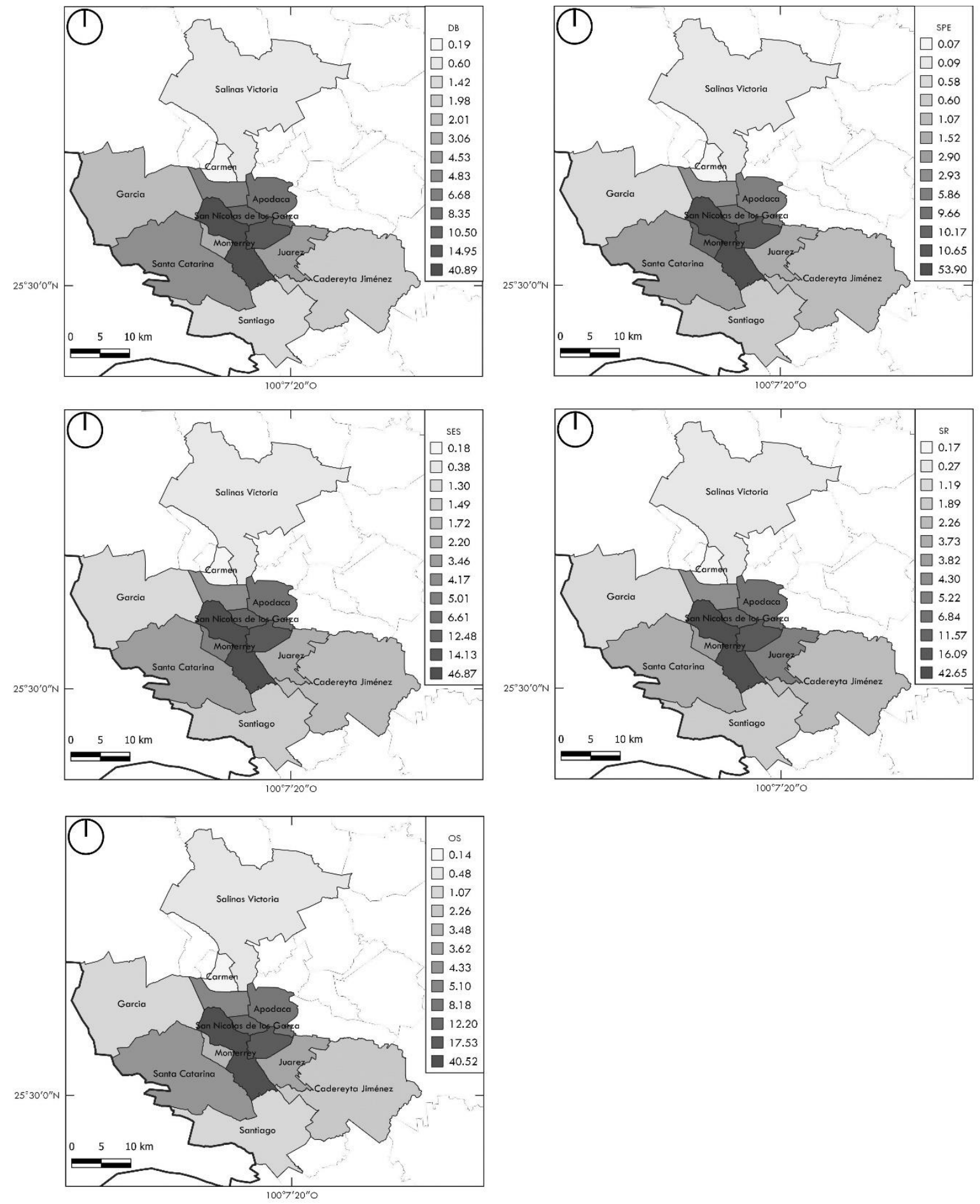

Figura 6. Distribución geográfica de unidades económicas terciarias, por sector, en la ZMM: distribución de bienes (DB), servicios profesionales especializados (SPE), servicios educativos y de salud (SES), servicios recreativos (SR), otros servicios (OS). 
Tabla 2. Unidades económicas de la ZMM en 2010, por municipio

\begin{tabular}{|c|c|c|c|c|}
\hline $\mathrm{N}^{\circ}$ & $\begin{array}{l}\text { Clave geográfica } \\
\text { según INEGI }\end{array}$ & Municipio & Total de UE & UE terciarias \\
\hline 1 & 19006 & Apodaca & 10574 & 9564 \\
\hline 2 & 19009 & Cadereyta Jiménez & 2706 & 2480 \\
\hline 3 & 19010 & Carmen & 247 & 212 \\
\hline 4 & 19018 & García & 2031 & 1893 \\
\hline 5 & 19019 & San Pedro & 5351 & 5006 \\
\hline 6 & 19021 & Escobedo & 7443 & 6772 \\
\hline 7 & 19026 & Guadalupe & 20722 & 18601 \\
\hline 8 & 19031 & Juárez & 5268 & 4913 \\
\hline 9 & 19039 & Monterrey & 57752 & 51847 \\
\hline 10 & 19045 & Salinas Victoria & 665 & 611 \\
\hline 11 & 19046 & San Nicolás & 15031 & 13568 \\
\hline 12 & 19048 & Santa Catarina & 5912 & 5305 \\
\hline 13 & 19049 & Santiago & 1846 & 1680 \\
\hline
\end{tabular}

Fuente: elaboración propia a partir de los datos del DENUE (INEGI, 2010a).

Con estas consideraciones, las Figuras 7 y 8 ponen de manifiesto datos muy distintos a los vistos hasta este momento. Lo primero que hay que resaltar son las altas tasas de UE que cada municipio destina a la actividad terciaria, tema que ya se apreciaba en la primera serie de mapas (Figuras 36): en promedio, el $90.87 \%$ de los establecimientos de la ZMM brinda algún tipo de servicio, frente al $9.07 \%$ dirigido a la transformación de bienes, tarea propia de la actividad secundaria. Como es de esperarse, ambos mapas son complementarios (Figuras 7 y 8), puesto que los municipios que encabezan la actividad secundaria ocupan los últimos sitios en la actividad terciaria.

El segundo hecho relevante es que Monterrey se ve desplazado del primer sitio. En la Figura 7 aparecen los municipios de Carmen, Santa Catarina, Guadalupe y Monterrey, en orden descendente, con tasas de UE de índole industrial superiores al 10\%. Aunque Cadereyta no figura en los primeros lugares de esta lista, merece mención la refinería de Petróleos Mexicanos (PEMEX) que en ella se encuentra.

Mientras tanto, la Figura 8 presenta a San Pedro, Juárez y García, igualmente en orden descendente, con tasas que sobrepasan el $93 \%$ de UE de giro terciario. Carmen encabeza la lista de los sectores manufactureros y San Pedro hace lo propio en la de los de servicios. Lo anterior tiene sentido si atendemos a la reciente anexión de Carmen a la ZMM, situación que pudiera significar un relativo 'rezago' en su incorporación a la terciarización, lo que asimismo supondría una mayor atención a la práctica manufacturera. Por otro lado, el primer puesto que San Pedro ostenta en lo que respecta a la oferta de servicios se explica a partir del destacado papel que este municipio juega, a nivel metropolitano, en la educación, la salud, las finanzas y los servicios especializados. 
Fuente: Elaboración propia a partir de los datos del DENUE (INEGI, 2010a).

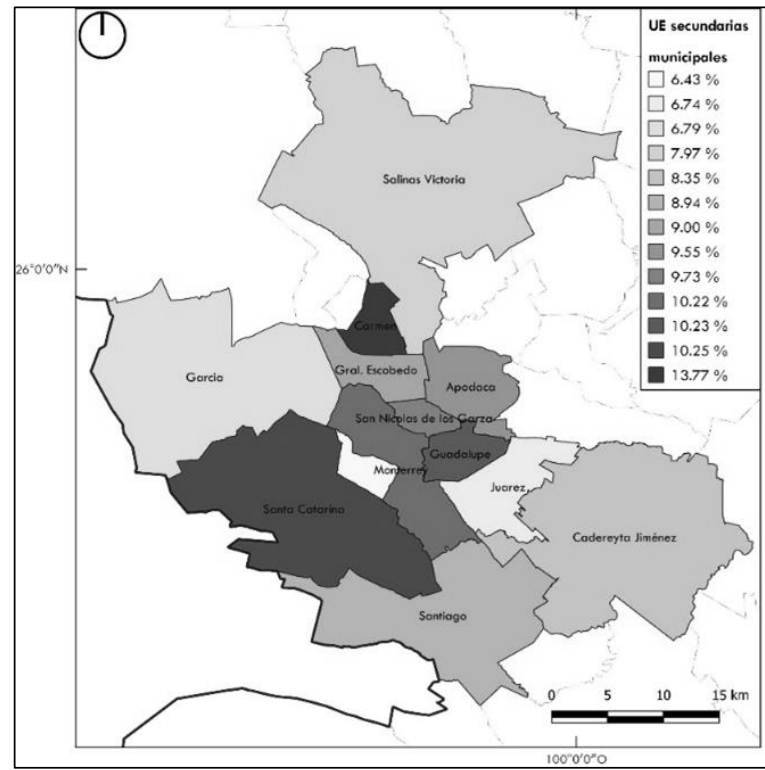

Figura 7. Tasas municipales de unidades económicas dedicadas a la actividad secundaria en la zona metropolitana de Monterrey (ZMM).

Fuente: Elaboración propia a partir de los datos del DENUE (INEGI, 2010a).

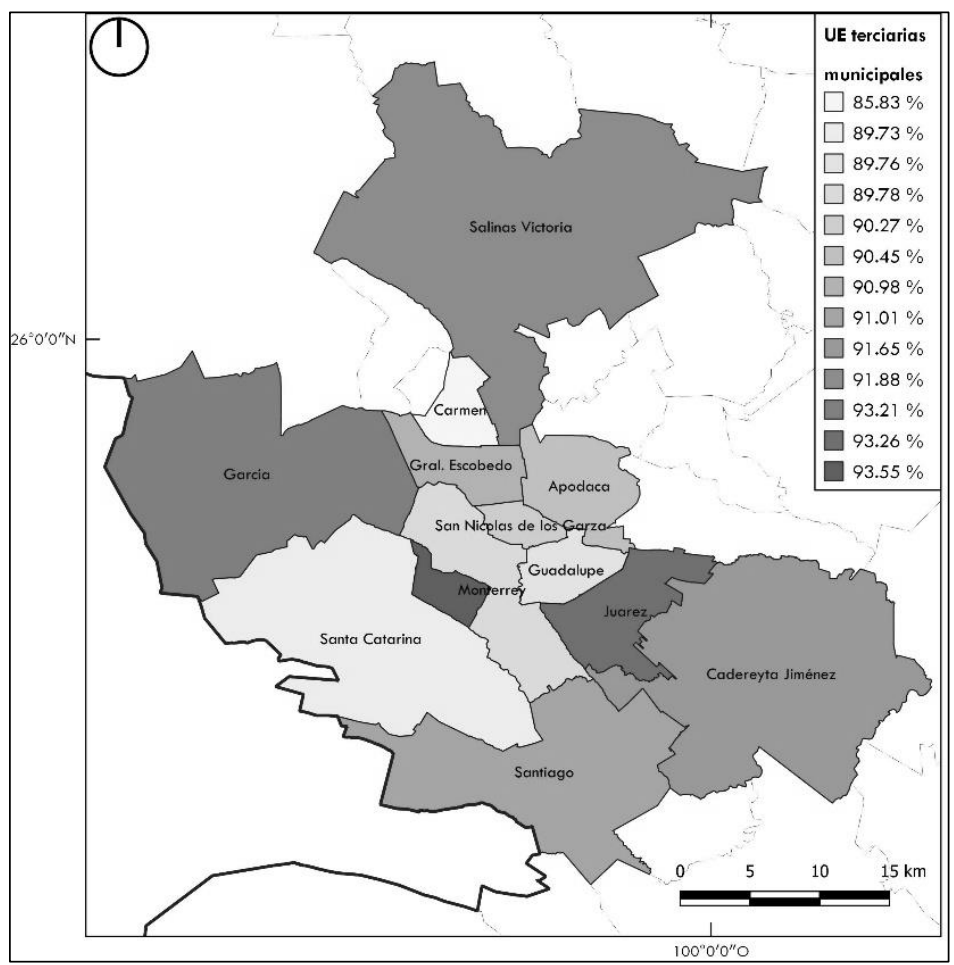

Figura 8. Tasas municipales de unidades económicas dedicadas a la actividad terciaria en la zona metropolitana de Monterrey (ZMM). 
De igual forma que en la primera serie mapas temáticos (Figuras 3-6), es pertinente desagregar la actividad terciaria por sectores de actividad. En consecuencia, se presenta la Figura 9.

El dato más evidente que se obtiene de dicha desagregación es el gran porcentaje de UE de la ZMM dirigidas a la DB. Con una tasa promedio del 52.59\%, es factible afirmar que la actividad comercial es la base de la economía terciaria regiomontana. Al mismo tiempo, si se toma en cuenta que son muchas más las UE involucradas en el giro terciario o de servicios (122.452) que en el secundario o industrial (13.083), es posible aseverar que el comercio es fundamental para la actividad económica en general de esta zona del país.

Lo anterior va de la mano con los señalamientos de Vásquez (2009) en lo que se refiere al importante papel de los servicios y el comercio al productor (comercio mayorista) en la ZMM. En el período que va de 1980 a 2003, tales actividades reportaron los porcentajes más altos de entre todos los sectores económicos en términos del PIB y de creación de empleos, no obstante que poseen un número menor de establecimientos que el de las orientadas al consumidor final (comercio minorista), tal y como lo demuestran las cifras del DENUE (INEGI, 2010a) utilizadas para la elaboración de los mapas temáticos en discusión; la Tabla 3 da cuenta de ello.

De cualquier modo, ya sea al mayoreo o al menudeo, los números apuntan al comercio como la práctica económica protagónica de la ZMM.

Tabla 3. Total de unidades económicas por sector de actividad terciaria en 2010. Zona metropolitana de Monterrey

\begin{tabular}{|c|c|}
\hline Sectores de actividad terciaria & Total de UE en la ZMM \\
\hline DB & 60779 \\
\hline Comercio mayorista & 5837 \\
\hline Comercio minorista & 54138 \\
\hline Transportes, correos y almacenamiento & 804 \\
\hline OI & 616 \\
\hline OA & 3700 \\
\hline SPE & 7373 \\
\hline SES & 11057 \\
\hline SR & 14304 \\
\hline OS & 21877 \\
\hline
\end{tabular}

Fuente: Elaboración propia a partir de los datos del DENUE (INEGI, 2010a).

En lo tocante a la posición que ocupan los distintos municipios de acuerdo con las tasas de UE destinadas a la DB destacan García y Salinas Victoria con valores que rebasan el 60\% (Figura 9). Les siguen muy de cerca y en orden descendente los municipios de Escobedo, Juárez, Santa Catarina, Carmen, Apodaca y Santiago con tasas mayores al 50\%. Se vislumbra pues un patrón espacial que concentra gran cantidad de actividad mercantil en la periferia norte de la ZMM. Una de las explicaciones de esta aglomeración podría ser la fuerte relación comercial con Estados Unidos de Norteamérica, relación en la que los territorios del ala norte metropolitana fungirían como las puertas de salida de mercancías hacia las vías que comunican el noreste mexicano con 
aquel país. Mención obligada es el Aeropuerto Internacional General Mariano Escobedo, en Apodaca, el más importante no solo de la metrópoli, sino del estado.

Fuente: Elaboración propia a partir de los datos del DENUE (INEGI, 2010a)
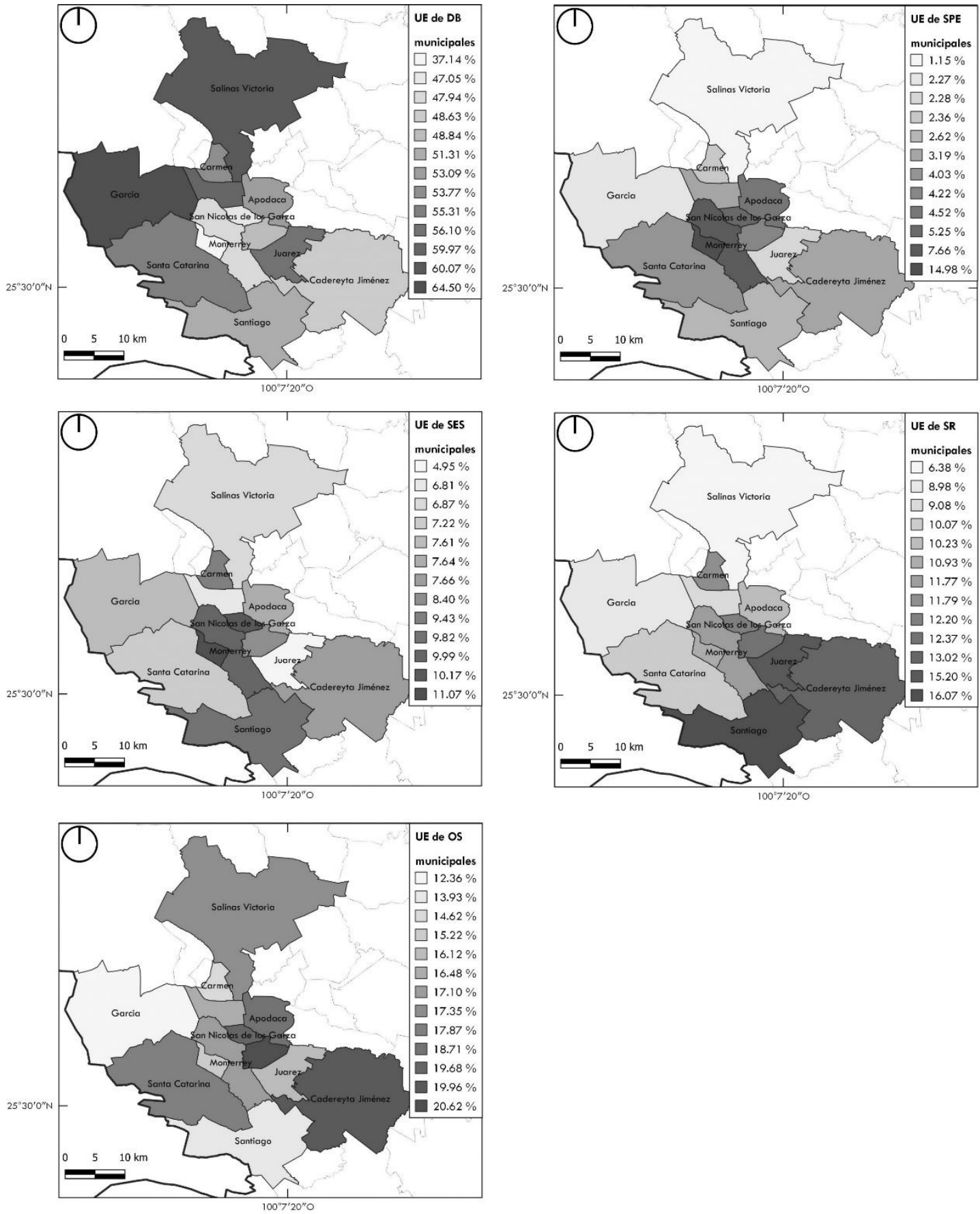

Figura 9. Tasas municipales de unidades económicas terciarias, por sector, en la ZMM: distribución de bienes (DB), servicios profesionales especializados (SPE), servicios educativos y de salud (SES), servicios recreativos (SR), otros servicios (OS). 
En el caso de Juárez y Santiago, al suroriente, la importante presencia de UE de giro comercial puede deberse al hecho de que ambos han sido suelo socorrido, junto con la mencionada periferia norte, por la población con necesidades de vivienda de clase social trabajadora (Juárez) y de clase media alta y alta (sureste de Monterrey, norte de Santiago), asunto que estimula el surgimiento de la actividad comercial. Puntos importantes conectados con ello son, por ejemplo, el crecimiento poblacional de Juárez que, del año 2000 al 2010, experimentó una tasa anual del 14\% (SEDESOL et al., 2012) (pasó de 66.497 a 256.970 habitantes); o el incuestionable crecimiento de la mancha urbana hacia el sureste metropolitano, entre la década de 1980 y principios del siglo XXI, cuyo principal impulsor fue el asentamiento de la población.

Si se deja de lado el sector de la DB, surgen circunstancias interesantes que hablan del perfil económico y funcional de cada municipio y que es preciso comentar.

En el mapa concerniente a los SPE, de la misma Figura 9, San Pedro aparece al comienzo de la relación de tasas de UE por municipio enfocadas en esta clase de servicios, con un poco más de 7 puntos porcentuales por arriba del segundo de la lista, el municipio de Monterrey. Este es el sector, de todos los que integran la actividad terciaria, en donde se observa la mayor diferencia entre las tasas del primero y el segundo puesto.

Lo mismo sucede en el mapa dedicado a los SES: nuevamente, San Pedro se localiza en el primer sitio de la lista de las tasas municipales de UE de este giro, en la que aparece con el $11.07 \%$ de sus establecimientos vinculados a la educación o a la salud, acompañado de San Nicolás de los Garza en los únicos dos puestos que superan los diez puntos porcentuales.

La convergencia de UE ligadas a los SPE y a los SES en la demarcación de San Pedro Garza García corrobora la vocación de este municipio para los servicios, específicamente para los SPE, lo que resulta afín a la caracterización que sobre él se hizo a la mitad de la década de 1990 (García, 1995), y que en los últimos años se ha visto materializada en el distrito de negocios localizado en este mismo municipio.

Puesta la atención ahora en los SR misma Figura 9, se distingue la periferia metropolitana sursureste con los municipios de Santiago, Juárez y Cadereyta Jiménez, en ese orden, a la cabeza del grupo de tasas de UE correspondiente. Sumado a lo apuntado sobre Santiago y Juárez acerca de suponer para la ZMM superficie para la vivienda-lo que estimularía la oferta de servicios dedicados al ocio y el esparcimiento-esta región estaría influenciada por varios de los principales atractivos turísticos localizados en las inmediaciones metropolitanas. Algunos de ellos son: el trazo y la arquitectura de la propia Villa de Santiago, las cascadas conocidas como Potrero Redondo y Cola de Caballo, la presa Ing. Rodrigo Gómez, o Presa La Boca, junto con su complejo turístico Bahía Escondida, Laguna de Sánchez (Díaz, 2001), entre varios otros.

Finalmente, los OS, para los que no se distingue un comportamiento espacial determinado dentro de la ZMM. Esta circunstancia puede explicarse si se reconoce que los servicios que integran esta categoría satisfacen necesidades del todo comunes para el consumidor final como el mantenimiento y la reparación de artículos varios, incluidos los domésticos, así como la asistencia en actividades personales y del hogar. El rango de las tasas de UE relacionadas con este tipo de tareas va del $12.36 \%$ al $20.62 \%$, en donde el primer valor corresponde al municipio de García y el segundo al de Guadalupe. 
Ahora bien, este panorama metropolitano de corte funcional no estaría completo sin un último grupo de mapas que refleje las zonas en donde la población está residiendo, puesto que las dos series hasta ahora expuestas (Figuras 3-6) y las Figuras 7-9 han proyectado únicamente las zonas geográficas en donde emplearse, descansar y hacerse de los servicios más elementales que la vida cotidiana demanda. Por lo tanto, se decide incluir en este apartado a las Figuras 10 y 11.

La Figura 10 se basa en las tasas de crecimiento poblacional, para el lapso de 2000 a 2010, dadas por la SEDESOL et. al (2012), y tiene por objeto identificar a los municipios de la ZMM en donde la tendencia de la población a asentarse ha sido más alta en los últimos años. En él se ve a los municipios de García y Juárez encabezando la lista con tasas promedio anuales por encima de los diez puntos porcentuales, seguidos de Carmen, Apodaca, Salinas Victoria y Escobedo, los que pasan de los cuatro puntos. Esto permite notar un claro patrón de crecimiento poblacional hacia el norte metropolitano, pues cinco de los seis municipios punteros se localizan en este punto cardinal. Por su parte, la Figura 11 reproduce los porcentajes de la población ocupada que labora en un municipio distinto al que reside para 2010, proporcionados de nueva cuenta por la SEDESOL et. al (2012), con el fin de tener una información más puntual sobre los territorios cuya participación metropolitana se vincula mayormente con la función de habitar. Los municipios que observan más del $50 \%$ de su población laborando fuera del municipio de residencia son Juárez, García, Escobedo y San Nicolás, de entre los que sobresale Juárez con el 71.1\% de sus habitantes en esta condición. Es importante señalar que los municipios que aparecen detrás de los ya mencionados son Guadalupe, Apodaca, Carmen y Santa Catarina, con valores mayores al 40\%, pero menores al 50\%. De este último enunciado hay que hacer notar, nuevamente, el hecho de que Guadalupe ha ido de funcionar como área dormitorio de la ZMM en la década de 1990 (Pozas, 1995), a emplear al 52.5\% de sus habitantes en 2010, esto es, 4.2 puntos más que San Nicolás, tradicionalmente relacionado con el sector manufacturero, es decir, ofertante de trabajo.

Si se combinan los señalamientos efectuados a ambos mapas, se vislumbra a Juárez y a García como las nuevas zonas habitacionales o dormitorio de la ZMM, pues en años recientes la tendencia poblacional a alojarse en estos municipios, conjugada con el empleo extra municipal de la mayoría de sus residentes, es evidente. De acuerdo con el INEGI (2011), "Juárez y García registran los incrementos mayores equivalentes a cuatro y cinco veces más de su población durante la última década". Incluso se podría contar a Escobedo como uno más de estos territorios, en consideración

a su casi $60 \%$ de pobladores con actividad económica fuera de su demarcación. Tanto Juárez como Escobedo estarían así dando continuidad a sus roles de contorno y reserva habitacional, respectivamente, con los que se les identificaba en la década de 1990 (Garza, 1995b; Rivera, 1995a), mientras que la incursión de García manifiesta de manera franca la imperante necesidad de suelo habitacional que la metrópoli demanda ante su acelerado crecimiento poblacional.

Se encuentra que, al contemplar los señalamientos sobre las tres series de mapas temáticos (Figuras 3-6; Figuras 7-9; y Figuras 10-11) generados por esta investigación con base en el DENUE (INEGI, 2010a) y en algunos indicadores brindados por la SEDESOL et. al (2012), la ZMM presenta la siguiente configuración: 
Fuente: Elaboración propia a partir de los datos establecidos por la SEDESOL et. al (2012).

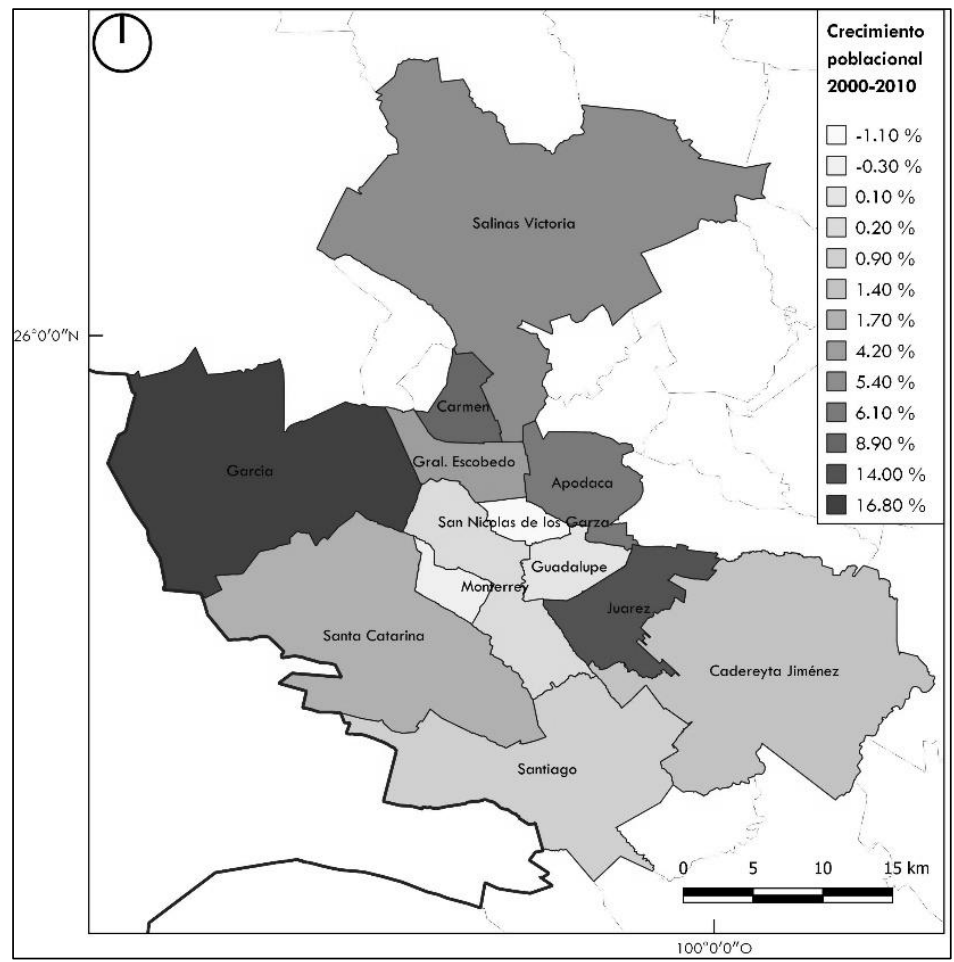

Figura 10. Tasas municipales de crecimiento poblacional medio anual de 2000 a 2010 . Zona metropolitana de Monterrey.

Fuente: Elaboración propia a partir de los datos establecidos por la SEDESOL et. al (2012).

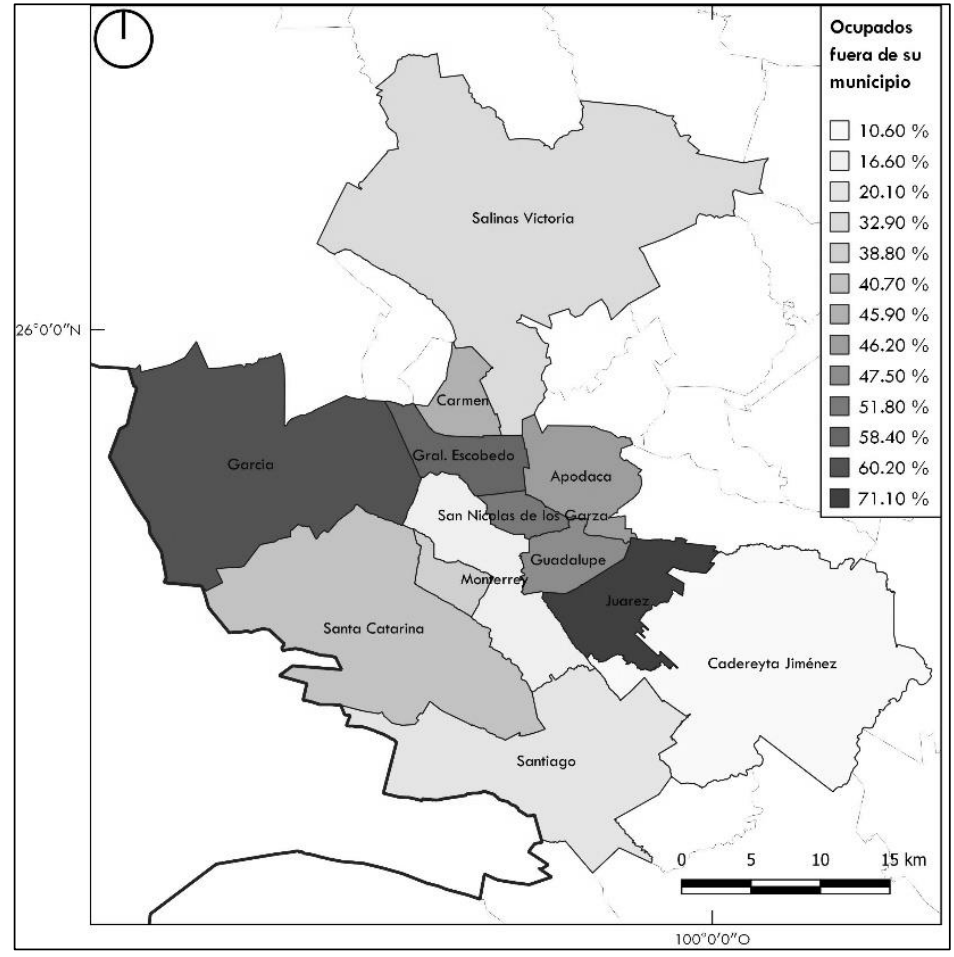

Figura 11. Porcentajes municipales de la población ocupada que en 2010 trabajaba fuera del municipio en el que residía. Zona metropolitana de Monterrey. 
1. Centro urbano: dominio indudable del municipio de Monterrey, papel ahora compartido con los municipios de Guadalupe y San Nicolás de los Garza, demarcaciones situadas al centro geográfico de la ZMM.

2. Zona habitacional: esta función urbana actualmente es desempeñada por los municipios de Juárez, al sureste, y de García y Escobedo, al noroeste y norte metropolitanos, respectivamente.

3. Zona industrial: aunque no se puede negar la importancia de los municipios centrales de Monterrey, Guadalupe y San Nicolás en la actividad industrial, demarcaciones como Carmen y Santa Catarina se destacan en este giro.

4. Distrito financiero y de negocios: San Pedro Garza García se ha convertido en la antonomasia de la actividad terciaria regiomontana, particularmente de los servicios profesionales especializados, circunstancia que concuerda con el emplazamiento del distrito financiero y de negocios de la ZMM dentro de los límites de esta municipalidad.

5. Servicios educativos y de salud: el rol protagónico en la oferta de esta clase de servicios lo comparten San Pedro, San Nicolás y Monterrey.

6. Actividad comercial: en este rubro sobresale la periferia norte de la metrópoli con municipios como García, Salinas Victoria, General Escobedo, Santa Catarina y Apodaca.

7. Zona de ocio y de descanso: la periferia sur-sureste figura en las primeras posiciones de la lista de ofertantes de servicios recreativos con municipios como Santiago, Juárez y Cadereyta Jiménez. La Figura 12 representa esquemáticamente la zonificación planteada para la ZMM.

\section{Conclusiones}

Se está consciente de que la aproximación metodológica aquí brindada es solo una posibilidad entre otras, y que esta se valió de la actividad económica, representada por el sector económico de sus UE, como único indicador para la diferenciación de las funciones urbanas de la ZMM. Sin duda, la consideración de indicadores de otra índole llevará a resultados distintos o más completos. A pesar de ello, la metodología descrita es una propuesta rigurosa y valiosa que permite acercamientos a la realidad urbana de cualquier ciudad o asentamiento que cuente con información similar a la analizada.

A partir de lo anterior, se declara que la condición de territorio dividido en sus funciones urbanas ha sido establecida por este estudio para la ZMM, lo que confirma la hipótesis ofrecida en la sección introductoria.

Cuestiones a resaltar son las siguientes. Es de admirar el caso de Guadalupe, municipio que de ser considerada área dormitorio (Pozas, 1995) en la década de 1990, para 2010 adquirió la significación suficiente como para conformar, junto con San Nicolás y Monterrey, la centralidad urbana de la ZMM, así como para convertirse en un importante ofertante de trabajo.

Otra sorpresa es el municipio de Carmen, cuya actividad manufacturera es relativamente considerable, a pesar de no figurar como territorio metropolitano tan solo diez años atrás SEDESOL et. al (2004).

Por otra parte, cuestiones vaticinadas desde los años de 1990, para 2010 se materializaron. Si antaño la economía de Santa Catarina, por ejemplo, ya tenía rasgos del tipo fabril (Rivera, 1995c), esta actividad se afianzó en 2010. Por otra parte, municipios periféricos como Escobedo o Juárez 
que vislumbraban un futuro uso habitacional (Garza, 1995b; Rivera, 1995a), para 2010 devinieron precisamente en zonas dormitorio.

Fuente: Elaboración propia.

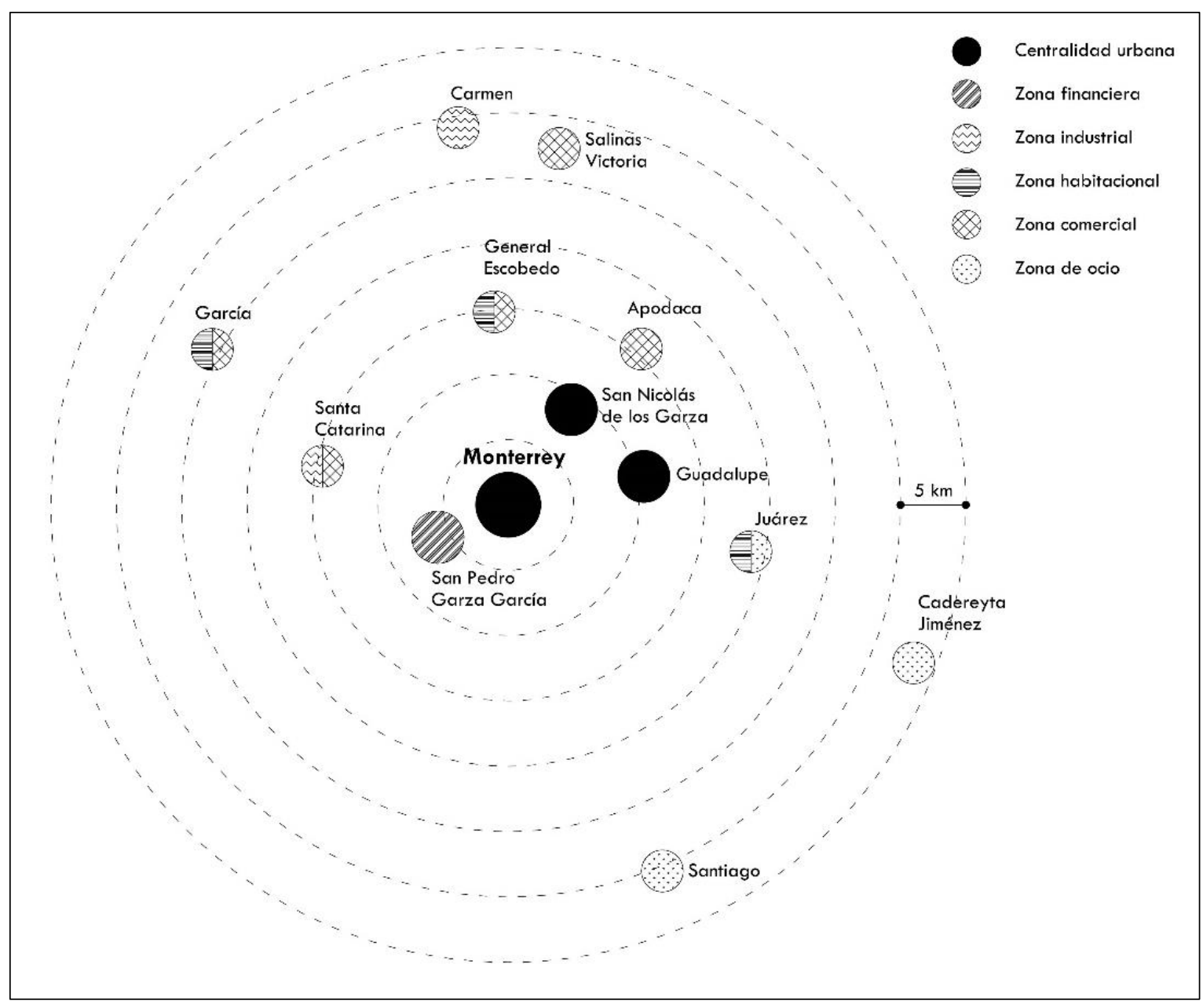

Figura 12. Esquema de la zonificación de la ZMM en 2010.

Ahora bien, tras revisar la disposición o configuración de las zonas identificadas en este estudio, se advierte la gran concentración manufacturera y de servicios en los municipios de Monterrey, San Nicolás y Guadalupe, así como en el de San Pedro, especializado en los servicios educativos y de la salud (SES) y en los profesionales especializados (SPE). Lo anterior permite afirmar que, como muchas de las metrópolis de la actualidad, la ZMM no solo observa una separación de sus funciones urbanas identificadas en cada uno de sus municipios, sino que, además, estas se encuentran geográficamente centralizadas, circunstancia desventajosa para la población asentada en la periferia, en donde la oferta laboral, el equipamiento urbano, los servicios, el transporte, la infraestructura, etc., son más escasos y de menor calidad.

De acuerdo con Sousa (2010), los ejercicios de investigación que buscan establecer zonificaciones al interior de territorios como el de la ZMM tienen aplicaciones prácticas relacionadas a la planeación urbana. Sin embargo, el principal cometido en esta ocasión es diametralmente distinto. 
Aunque no se cuenta con los elementos necesarios para aseverar que la zonificación de la ZMM cuenta entre una de sus causas a las relaciones sociales dadas por el género, este trabajo aspira a generar la reflexión en torno a posibles conexiones entre la separación funcional de la ciudad y las asunciones y modelos sociales relacionados con la asignación de espacios, físicos y sociales, a razón de esa categoría. Después de todo, la ZMM es un territorio zonificado acerca del que cabe preguntarse ¿tiene el género alguna incidencia en su organización espacial?

\section{REFERENCIAS BIBLIOGRÁFICAS}

Arredondo, F., Maldonado, V., \& Velázquez, L. M. (2013). Liderazgo femenino e innovación social. Mundo nиеvo. Revista de estudios latinoamericanos, (13), 207-226.

Beauvoir, S. de. (2005). El segundo sexo. Cátedra.

Borja, J., \& Muxí, Z. (2003). El espacio público: ciudad y ciudadanía. Electa.

Castells, M. (1978). La cuestión urbana. México, D.F.: Siglo XXI.

Castro, M. (2009). Género. Diccionario de estudios culturales latinoamericanos, (pp. 112-119). Siglo XXI Editores: Instituto Mora.

Cavazos, I. (1995). Breve historia de Nuevo León. México, D.F.: El Colegio de México, Fideicomiso Historia de las Américas, Fondo de Cultura Económica.

Cobo, R. (2014). Aproximaciones a la teoría crítica feminista. Lima: Comité de América Latina y el Caribe para la Defensa de los Derechos de las Mujeres.

Col-lectiu Punt 6. (2019). Urbanismo feminista. Por una transformación radical de los espacios de vida. Virus.

Connell, R. (2005). Work/Life balance, gender equity and social change. Australian Journal of Social Issues, 40(3), 369-383. https://doi.org/10.1002/j.1839-4655.2005.tb00978.x

Contreras, C. (2007). Geografía de Nuevo León. Fondo Editorial de Nuevo León.

Cuvardic, D. (2011). La flaneuse en la historia de la cultura occidental. Filología y lingüística, 37(1), 67-95. Doi:10.15517/RFL.V37I1.2350

Darke, J. (1998). La ciudad modelada por el varón. En C. Booth, \& J. Darke (Eds.), La vida de las mujeres en las ciudades: la ciudad, un espacio para el cambio (pp. 115-130). Narcea.

Díaz, J. R. R. (2001). Villa de Santiago, N. L. Serie: el terruño... 2. Villa de Santiago, N. L.: Universidad Autónoma de Nuevo León.

García, C. (2016). Teorías e historia de la ciudad contemporánea. Editorial Gustavo Gili, SL.

García, R. (1995). San Pedro Garza García: área residencial y de servicios. En G. Garza (Ed.), Atlas de Monterrey (pp. 355-361). El Colegio de México.

García, R., \& Garza, G. (1995). Monterrey: centralidad urbana. En G. Garza (Ed.), Atlas de Monterrey (pp. 325-331). El Colegio de México.

Garza, G. (1995a). Atlas de Monterrey. El Colegio de México.

Garza, G. (1995b). Juárez: contorno habitacional e industrial. En G. Garza (Ed.), Atlas de Monterrey (pp. 376-382). El Colegio de México.

Garza, G. (2004). Reseña de "Monterrey y Saltillo, hacia un nuevo modelo de planeación y gestión urbana metropolitana” de Roberto García Ortega. Estudios Demográficos y Urbanos, 19(3), 721-729. http://dx.doi.org/10.24201/edu.v19i3.1186 
Harvey, D. (2013). Ciudades rebeldes: del derecho de la ciudad a la revolución urbana. Ediciones Akal.

Hillier, B., \& Hanson, J. (1984). The Social Logic of Space. Cambridge: Cambridge University Press. Inam, A. (2013). Designing Urban Transformation. Routledge.

Instituto Nacional de Estadística y Geografía. INEGI. (2010a). Directorio estadístico nacional de unidades económicas. Entidad: Nuevo León. 2010. https://bit.ly/3fFNl3j

Instituto Nacional de Estadística y Geografía. INEGI. (2010b). Muestra (cuestionario ampliado). https://bit.ly/3pdE8Cx

Instituto Nacional de Estadística y Geografía. INEGI. (2010c). Norma técnica para la incorporación y actualización de información al Directorio estadístico nacional de unidades económicas. https://bit.ly/34Jwd6q

Instituto Nacional de Estadística y Geografía. INEGI. (2010d). Síntesis metodológica del sistema de clasificación industrial de América del Norte, México. SCIAN 2007. Aguascalientes: Instituto Nacional de Estadística y Geografía.

Instituto Nacional de Estadística y Geografía. INEGI. (2010e). Sistema para la consulta de información censal (SCINCE Versión 05/2012). https://bit.ly/2TEkXGj

Instituto Nacional de Estadística y Geografía. INEGI. (2011). Principales resultados del censo de población y vivienda 2010. Nuevo León. Aguascalientes: Instituto Nacional de Estadística y Geografía.

Karsten, L., \& Meertens, D. (1992). La geografia del género: sobre visibilidad, identidad y relaciones de poder. Documents d'anàlisi geogràfica, (19-20), 181-193.

Lefebvre, H. (1978). El derecho a la ciudad. Ediciones Península.

Lezama, J. L. (2014). Teoría social, espacio y ciudad. México, El Colegio de México.

Massey, D. B. (1994). Space, place, and gender. Polity Press.

Mcdowell, L. (2000). Género, identidad y lugar: un estudio de las geografías feministas. Ediciones Cátedra.

Moser, C. O. N. (1989). Gender planning in the third world: Meeting practical and strategic gender needs. World Development, 17(11), 1799-1825. https://doi.org/10.1016/0305$750 X(89) 90201-5$

Mumford, L. (1961). The City in History: Its Origins, Its Transformations, and Its Prospects. Harcourt, Brace \& World.

Pozas, M. de los Á. (1995). Guadalupe: zona habitacional. En G. Garza (Ed.), Atlas de Monterrey (pp. 332-339). El Colegio de México.

Rivera, S. (1995a). General Escobedo: reserva habitacional. En G. Garza (Ed.), Atlas de Monterrey (pp. 362-368). El Colegio de México.

Rivera, S. (1995b). San Nicolás de los Garza: predominio industrial. En G. Garza (Ed.), Atlas de Monterrey (pp. 340-347). El Colegio de México.

Rivera, S. (1995c). Santa Catarina: contorno industrial. En G. Garza (Ed.), Atlas de Monterrey (pp. 348-354). El Colegio de México.

Saborido, M. (1999). Ciudad y relaciones de género. Lima: CEPAL. Octava Conferencia Regional sobre la Mujer de América Latina y el Caribe. 
Sassen, S. (Enero 31, 2014). La ciudad global: introducción a un concepto. Globalización. https://bit.ly/3fI6Fgd

Secretaría de Desarrollo Social., Consejo Nacional de Población., Instituto Nacional de Estadística., \& Geografía e Informática. SEDESOL, CONAPO, \& INEGI. (2004). Delimitación de las zonas metropolitanas de México. Aguascalientes.

Secretaría de Desarrollo Social., Consejo Nacional de Población., Instituto Nacional de Estadística., \& Geografía e Informática. SEDESOL, CONAPO, \& INEGI. (2012). Delimitación de las zonas metropolitanas de México 2010. Aguascalientes.

Sewell, J. E. (2011). Women and the Everyday City: Public Space in San Francisco, 1890-1915. University of Minnesota Press.

Sobrino, J. (2003). Zonas metropolitanas de México en 2000: conformación territorial y movilidad de la población ocupada. Estudios Demográficos y Urbanos, 18(3), 461-507. http://dx.doi.org/10.24201/edu.v18i3.1156

Soja, E. W. (1996). Thirdspace: journeys to Los Angeles and other real-and-imagined places. Blackwell Publishers.

Sousa, E. (2010). La zonificación de áreas metropolitanas en la contemporaneidad lationoamericana. Urbano, 13(22), 78-86.

Valcárcel, A. (2009). Feminismo en el mundo global. Cátedra.

Vásquez, B. I. (2009). Una visión mítica de estado industrial: la hegemonía del sector terciario en las ciudades de Nuevo León, 1980-2003. En G. Garza \& J. Sobrino (Eds.), Evolución del sector servicios en ciudades y regiones de México (pp. 479-549). El Colegio de México.

Wilson, E. (1992). The sphinx in the city: urban life, the control of disorder, and women. University of California Press. 